\title{
Geotextile Encapsulation as Protection to Lime Column under Shear Load
}

\author{
Siaw Yah Chong ${ }^{1 *}$, Khairul Anuar Kassim² ${ }^{2}$, Min Lee Lee $^{3}$, and See Hung Lau ${ }^{1}$ \\ ${ }^{1}$ Lee Kong Chian Faculty of Engineering and Science, Universiti Tunku Abdul Rahman, Jalan Sungai \\ Long, Bandar Sungai Long, Cheras, 43000 Kajang, Selangor, Malaysia \\ ${ }^{2}$ Department of Geotechnics and Transportation, Faculty of Civil Engineering, Universiti Teknologi \\ Malaysia, 81310 UTM Johor Bahru, Johor, Malaysia \\ ${ }^{3}$ Department of Civil Engineering, Faculty of Engineering, University of Nothingham Malaysia, \\ 43500 Selangor, Malaysia
}

\begin{abstract}
Deep lime stabilization such as lime column, can effectively improve the problematic soft clay through stabilization, settlement reduction and embankment stabilization. Nevertheless, the reduction of lime column load capacity was often encountered due to the column lateral displacement which was induced by high lateral earth pressure in embankments and deep excavation. In order to protect and enhance the mobilization of lime column strength, geotextile encapsulation was proposed for lime column. In this study, large shear box tests were conducted on lime column and geotextile encapsulated lime column $(G E L C)$ stabilized Pontian marine clay samples with different column sizes and curing ages, in order to investigate the performance of geotextile encapsulation on lime column in Pontian marine clay under shear loading. It was found that geotextile encapsulation effectively increased the horizontal shear resistance of lime column and protected the column from defect due to lateral displacement, especially at early age when modification was still in process. Geotextile encapsulation also successfully protected lime column from shear and bending failure under lateral load.
\end{abstract}

\section{Introduction}

Deep lime stabilization such as lime column improves the problematic soft clay through stabilization, settlement reduction and embankment stabilization [1-6]. Shear failure and bending failure were normally observed on lime column under lateral load [7-11]. The lateral displacement significantly reduced lime column load capacity, especially for embankments with low stability and deep excavation which had high lateral pressure [1]. Geosynthetic encasement provides additional confining pressure to the granular column and effectively increased its performance in the soft clay $[2,3]$. In order to protect and enhance

\footnotetext{
* Corresponding author: chongsiawy@utar.edu.my
} 
the mobilization of lime column strength, geotextile encapsulation was proposed for lime column in this study.

This paper aimed to investigate the performance of geotextile encapsulation on lime column under shear load, including shear resistance and failure mechanisms. Physical modelling, namely large shear box tests were conducted. The samples tested are Pontian marine clay stabilized with lime column and GELC at different ages. Column with different sizes are also tested. The horizontal shear resistance and failure mode were observed. Improvement ratio was used to evaluate the performance of geotextile encapsulation on lime column stabilized Pontian marine clay under lateral load. Parameters which influenced the performance of geotextile encapsulation on lateral force resistance for lime column were investigated, including curing duration and area ratio.

\section{Material and methods}

\subsection{Materials}

Pontian marine clay obtained from Sg Penerok T/Kiri in Johor, Malaysia was selected as the soil specimen in this study. The sampling site is geographically located at coordinates of $\mathrm{N} 01^{\circ} 22.457^{\prime}$ and $\mathrm{E} 103^{\circ} 25.702^{\prime}$. The area is part of the coastal plain of southwestern region of Johor which is predominantly underlain by marine clay, silt and the paludal peat deposit of Holocene age [4]. Pontian marine clay has liquid limit of $62 \%$ and plastic limit of $30 \%$. It was classified as clay with high plasticity $(\mathrm{CH})$, based on the British Soil Classification System (BSCS). The soil has a specific gravity of $2.48 \mathrm{Mg} / \mathrm{m}^{3}$ and with the initial consumption of lime of $4.40 \%$. The stabilizer selected was hydrated lime supplied by Limetreats, a lime product manufacturer based in Pasir Gudang, Johor whereas the geotextile selected for encapsulation on the lime column was TenCate Polyfelt ${ }^{\circledR}$ PE50 from Tencate Geosynthetics Malaysia Sdn Bhd.

\subsection{Samples preparation}

First, Pontian marine clay was mixed with water to form slurry with moisture content of 1.2 times the liquid limit. Then, the slurry was poured into a cylinder with internal diameter of $210 \mathrm{~mm}$. An overburden pressure of $50 \mathrm{kPa}$ was applied onto the slurry for 3 days in order to form a $200 \mathrm{~mm}$ thick clay bed with vane shear strength about $20 \pm 2 \mathrm{kPa}$.

Lime columns of $200 \mathrm{~mm}$ in height were formed in 3 different diameters, i.e. $40 \mathrm{~mm}, 53$ $\mathrm{mm}$ and $60 \mathrm{~mm}$ by compacting lime-soil mixtures into $P V C$ tubes of the selected diameters in 3 layers at a bulk density of $1.74 \mathrm{Mg} / \mathrm{m}^{3}$. The lime content of the lime-soil mixture was $10 \%$, while the water content was controlled at $37 \%$. From the preliminary tests, the $14-$ day, 28-day and 56-day unconfined compressive strength of the lime columns was $264 \mathrm{kPa}$, $362 \mathrm{kPa}$, and $389 \mathrm{kPa}$, respectively [15].

For $G E L C$, the geotextile sheet was seamed into the required diameters and $200 \mathrm{~mm}$ sleeves. The soil-lime mixture with similar properties as those of the normal lime column was then compacted in three layers into the $P V C$ tubes that covered with the geotextile sleeve to form the GELC [16].

A hollow, sharp-ended cylindrical steel tube that attached to a $P V C$ casing was pushed into the center of the clay bed. Soil in the tube was removed and the pre-casted lime column was subsequently pushed into the hole to replace the soil extracted. Pontian marine clay sample with lime column and GELC were cured under room temperature for different curing periods, namely: 14 days, 28 days and 56 days before being tested. 


\subsection{Large shear box test procedures}

A series of large shear box tests were performed to evaluate the performance of the geotextile encapsulation on lime column under shear stresses. The testing setup was designed based on the unit cell concepts to simulate a number of columns installed at an identical spacing, in a triangular pattern. The area ratios (a) for the specimens were 0.036 , 0.064 and 0.082 .

Fig. 1 shows the schematic diagram of the large shear box. The shear box consisted of 2 separated shear rings with an inner diameter of $210 \mathrm{~mm}$. Fig. 2 shows the photograph of the shear ring taken from the top view. The upper part of the shear ring was fixed while the bottom part was unrestrained from any movement. The sample was sheared laterally until the lateral displacement exceeded $20 \%$ of the sample diameter. The strain rate applied was $1 \mathrm{~mm} / \mathrm{min}$. The sample was subjected to a normal stress of $8.65 \mathrm{kPa}$ throughout the test. The shear stress was measured by using load cell whereas the lateral displacement was measured by using linear variable differential transducer $(L V D T)$. Data acquisition system was used to record and retrieve the data for subsequent analysis. Upon completion of the shear tests, the samples were extruded and bisected to observe their failure pattern and deformation characteristics.

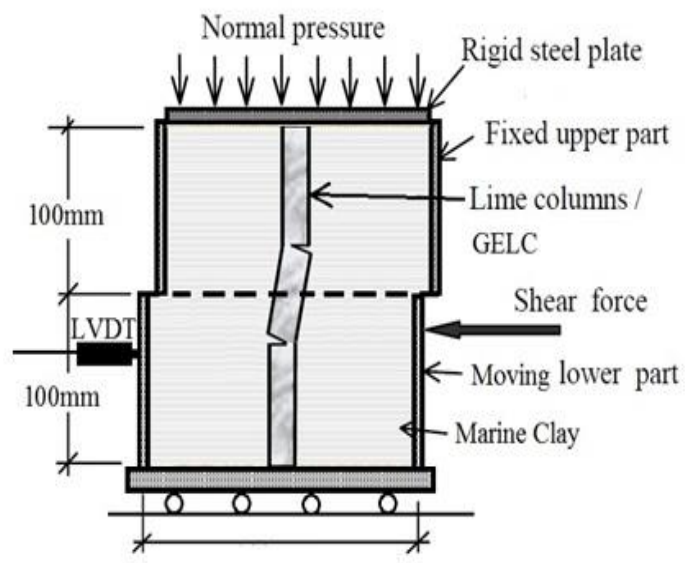

Fig. 1. Large shear box test setup

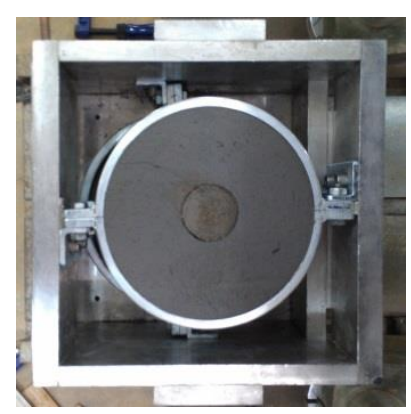

Fig. 2. Top elevation of big shear box 


\section{Results and discussion}

\subsection{Horizontal Shear Resistance Improvement Ratio (HSR)}

The peak shear stress obtained from the large shear box tests was defined as the horizontal shear resistance $(H S R)$. The performance of geotextile encapsulation on lime column stabilized Pontian marine clay was evaluated by comparing the horizontal resistance shear improvement ratio $(I R)$. Horizontal shear resistance improvement ratio is defined as the ratio of horizontal shear resistance of GELC stabilized sample ( $H S R_{\text {gelc }}$ ) to that of normal lime column stabilized marine clay $\left(H S R_{\mathrm{lc}}\right)$. The results for both $H S R$ and $I R$ are summarized in Table 1.

The HSR of lime column stabilized samples at age of 14 days with column diameter of $40 \mathrm{~mm}, 53 \mathrm{~mm}$ and $60 \mathrm{~mm}$ was $11.70 \mathrm{kPa}, 13.28 \mathrm{kPa}$ and $14.90 \mathrm{kPa}$, respectively. Then, the HSR for the sample at age of 56 days increased to $17.36 \mathrm{kPa}, 19.42 \mathrm{kPa}$ and $19.83 \mathrm{kPa}$, respectively. It was observed that the lime column stabilized marine clay had a greater increase in HSR from age 14 to 28 days than from age 28 to 56 days. This was because the lime-soil mixture was still in modification process in which the lime column is still in the process of gaining strength; the lime column at 14 days was still weak. This was supported by the results of unconfined compression test which also exhibited a similar trend.

Table 1. Horizontal shear resistances and improvement ratios of Pontian marine clay with lime column and GELC.

\begin{tabular}{|c|c|c|c|c|c|c|}
\hline $\begin{array}{c}\text { Column } \\
\text { Diameter, } \\
\varphi_{\text {col }}(\mathrm{mm})\end{array}$ & $\begin{array}{c}\text { Area Ratio, } \\
a \\
\text { (in fraction) }\end{array}$ & $\begin{array}{c}\text { Age, } \\
t(\text { day })\end{array}$ & $\begin{array}{c}\text { Unconfined } \\
\text { Compressive } \\
\text { Strength, } q_{\mathrm{u} \text { col }(\mathrm{kPa})}\end{array}$ & $\begin{array}{c}H S R_{\text {gelc }} \\
(\mathrm{kPa})\end{array}$ & $\begin{array}{c}H S R_{\mathrm{lc}} \\
(\mathrm{kPa})\end{array}$ & $\begin{array}{c}I R \\
\text { (in } \\
\text { fraction) }\end{array}$ \\
\hline 40 & 0.036 & 14 & 264 & 17.27 & 11.70 & 1.48 \\
\hline 40 & 0.036 & 28 & 362 & 16.11 & 15.77 & 1.02 \\
\hline 40 & 0.036 & 56 & 389 & 17.08 & 17.36 & 0.98 \\
\hline 53 & 0.064 & 14 & 264 & 17.51 & 13.28 & 1.32 \\
\hline 53 & 0.064 & 28 & 362 & 20.39 & 18.60 & 1.10 \\
\hline 53 & 0.064 & 56 & 389 & 18.16 & 19.42 & 0.94 \\
\hline 60 & 0.082 & 14 & 264 & 18.55 & 14.90 & 1.25 \\
\hline 60 & 0.082 & 28 & 362 & 20.44 & 19.69 & 1.04 \\
\hline 60 & 0.082 & 56 & 389 & 21.25 & 19.83 & 1.07 \\
\hline
\end{tabular}

The enhancement in HSR of lime columns that encapsulated with geotextile was further evaluated by assessing their $I R$ s. Two parameters which may affect the performance of the geotextile encapsulation were examined, namely curing duration and column size.

Fig. 3 presents the correlation between curing duration and $I R$ of GELC stabilized Pontian marine clay with different column diameters. For samples aged 14 days, the HSR of GELC samples with column diameters of $40 \mathrm{~mm}, 53 \mathrm{~mm}$ and $60 \mathrm{~mm}$ were improved by $48 \%, 32 \%$, and $25 \%$, respectively. However, the $I R$ decreased as the curing duration increased. The IRs were close to unity for the samples aged 56 days. A higher $I R$ was observed for samples at a younger age as the lime column was still weak and in modification process, especially for samples at the age of 14 days. It was anticipated that the geotextile could provide additional bonding to these weak columns. When the samples 
reached the age of 28 days, the lime column had almost achieved the optimum unconfined compressive strength and hence the improvement ratio for samples aged 28 days were relatively close to those of 56 days. From the foregoing results, it was found that geotextile encapsulation was effective in enhancing the short term performance of the lime columns stabilized soil during the early construction stage. An empirical correlation between horizontal shear resistance improvement ratio $(I R)$ due to geotextile encapsulation and sample curing duration ( $t$, in day) was developed:

$$
I R=2.3 t^{-0.2}
$$

It should be noted that the correlation may only be valid for GELC with lime content of $10 \%$ and other testing parameters as set in the present study. A larger sample size with different testing configurations is required to further validate the empirical equation.

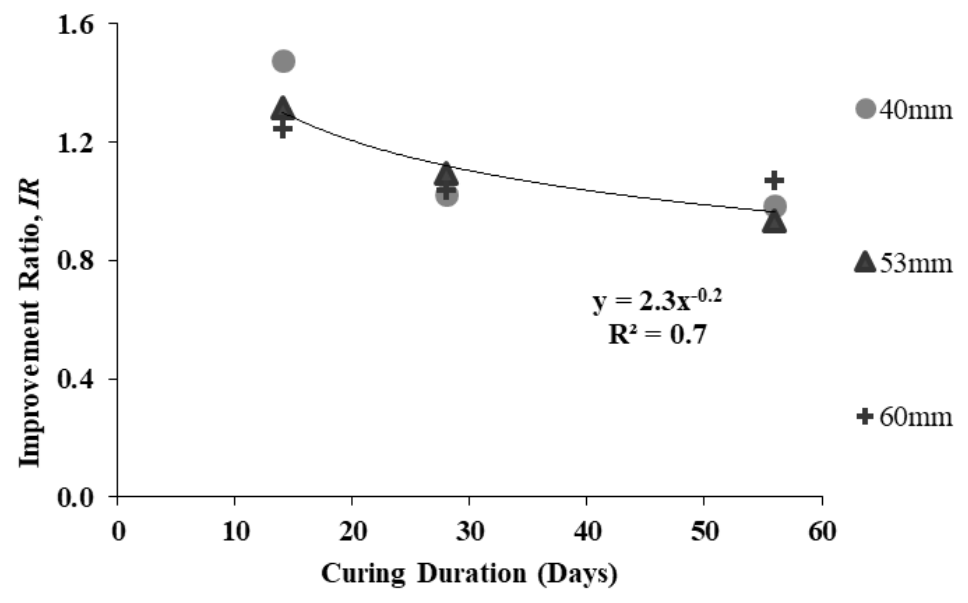

Fig. 3. Relationship between horizontal shear resistance improvement ratio and curing duration for GELC with different diameters

The effect of area ratio on $I R$ for samples at different ages is shown in Fig. 4. It was observed that for columns aged 14 days, the $I R$ decreased as area ratio increased (the $I R$ for GELC with area ratios of $0.04,0.06$ and 0.08 were $1.48,1.32$ and 1.25 , respectively). However, for columns aged 28 days and 56 days, the $I R$ did not exhibit clear relationship with area ratio. The $I R$ was close to unity, ranging from 0.94 to 1.10 . This showed that geotextile encapsulation was more effective on young aged lime column with smaller area ratio. 


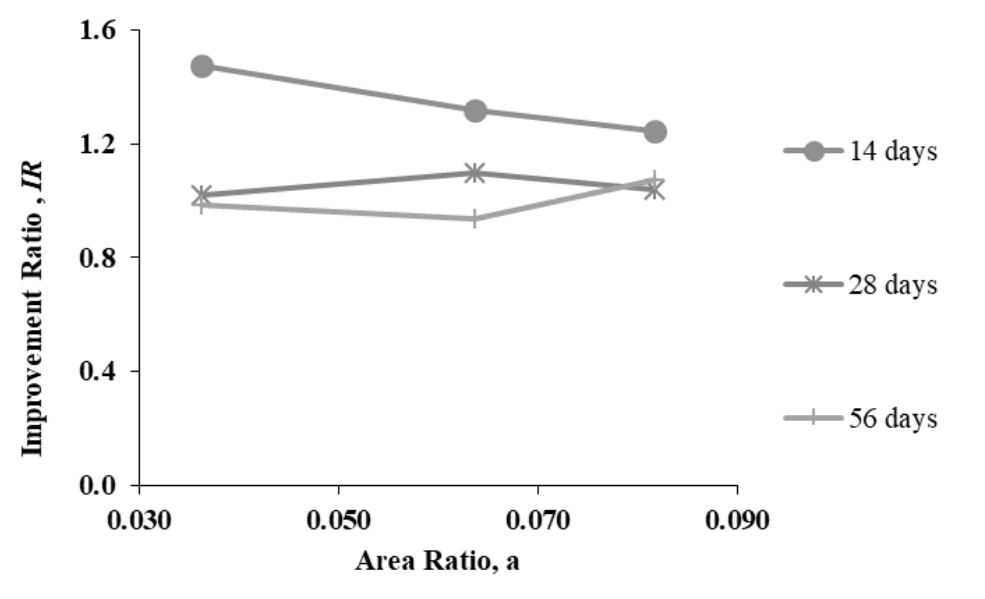

Fig. 4. Horizontal shear resistance improvement ratio due to geotextile encapsulation for sample at different ages versus area ratio

\subsection{Failure patterns}

Bisected samples of lime column stabilized Pontian marine clay upon completion of large shear box tests are shown in Figs. 5 to 7. Similar failure patterns were observed for lime column stabilized samples at the same age, regardless of the column size. Shear failure was observed for the lime column stabilized Pontian marine clay aged 14 and 28 days. Both column and surrounding soil failed along the pre-determined surface. This was because lime columns at a young age had lower strength and stiffness. Bending failure with 2 plastic hinges was observed for lime columns aged 56 days. The samples failed as the resistant capacity of the column against bending moment was exceeded. The plastic hinges were located at $25 \mathrm{~mm}$ above and below the shearing plane. When the lime column strength and moment resistance is relatively high, the column behaves as a pile or dowel in which the number of plastic hinges formed is dependent on the location of slip surface compared to the column length [5]. However, the surrounding soil experienced shear failure at the predetermined surface

Bisected samples for the GELC stabilized Pontian marine clay after the large shear box tests are shown in Figs. 8 to 10. It was observed that all the GELC stabilized samples had a similar failure mode, regardless of the column size and curing duration. No crack or failure was observed in the column itself. However, the column failed by rotation as the lateral resistance of surrounding soil exceeded. Kivelo and Brom found that for short columns with slip surface at half of the column length, and constant surrounding soil strength to depth, the column will rotate as a rigid mass [5].

Geotextile encapsulation had significantly influenced the failure mode of lime column under shear load test. From the testing results, it can be concluded that the columns without geotextile encapsulation failed by either shear or bending of the column materials. Geotextile encapsulation successfully protected lime columns and improved their shear and bending capacity. As the result, The GELC failed by rotation as a rigid body due to the exceeded lateral resistance of surrounding soil. 


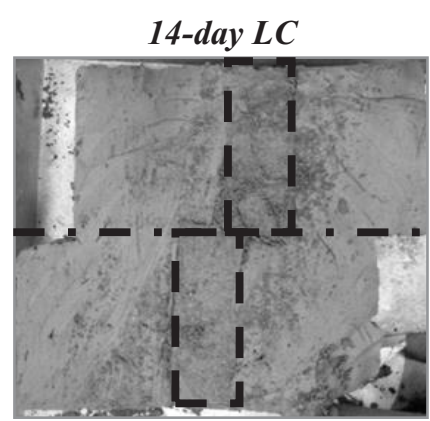

(i)

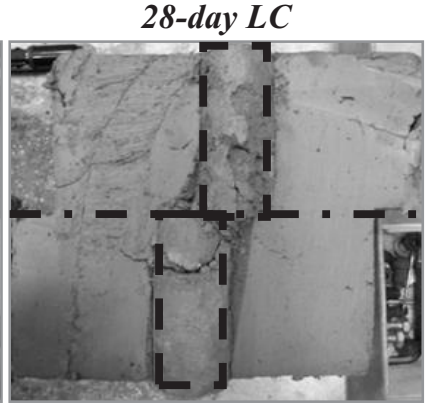

(ii)

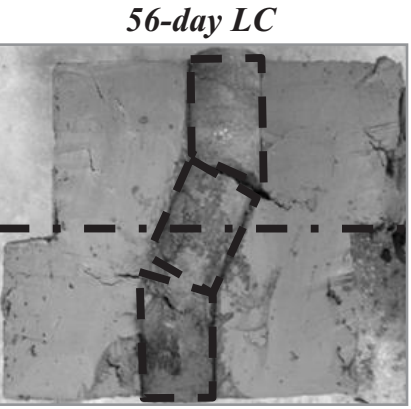

(iii)

Fig. 5. Bisected Pontian marine clay sample with $40 \mathrm{~mm}$ lime column

\section{4-day LC}

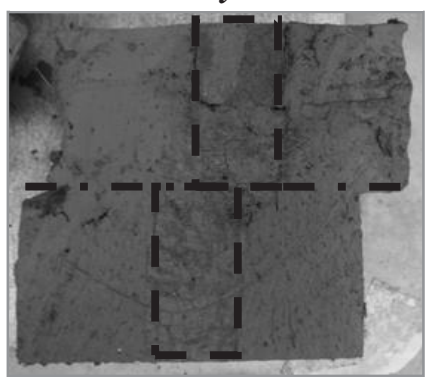

(i) 28-day LC

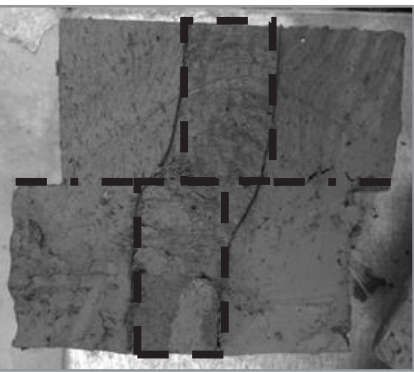

(ii) 56-day LC

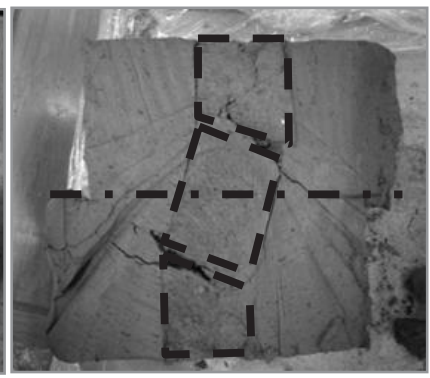

(iii)

Fig. 6. Bisected Pontian marine clay sample with $53 \mathrm{~mm}$ lime column

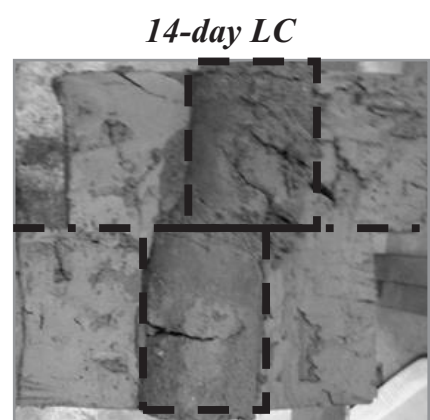

(i)

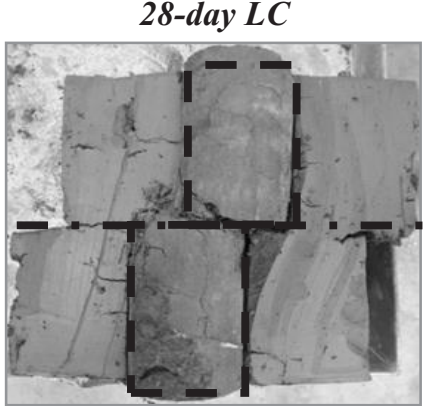

(ii) 56-day LC

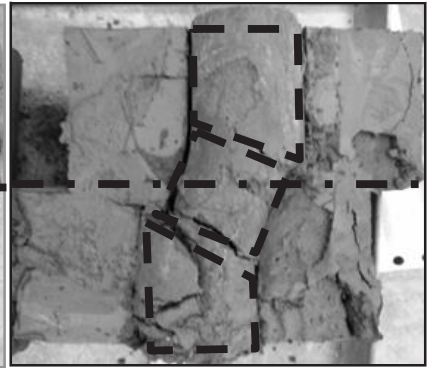

(iii)

Fig. 7. Bisected Pontian marine clay sample with $60 \mathrm{~mm}$ lime column 


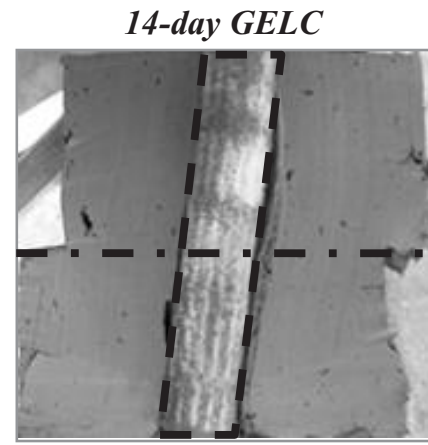

(i)

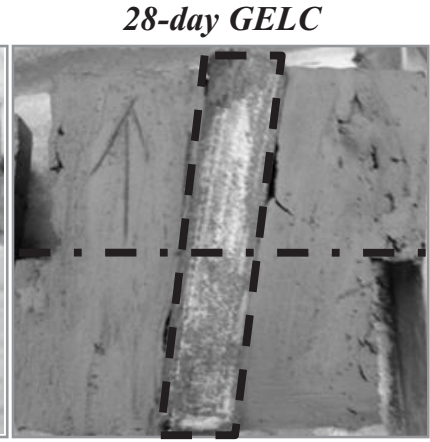

(ii)

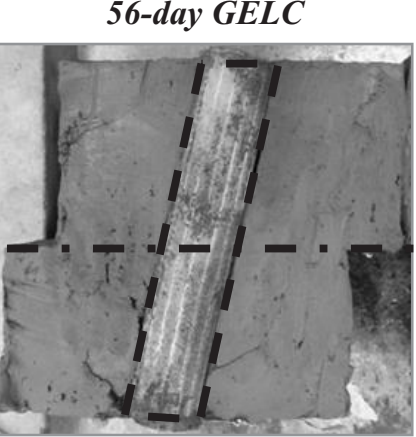

(iii)

Fig. 8. Bisected Pontian marine clay sample with $40 \mathrm{~mm}$ GELC

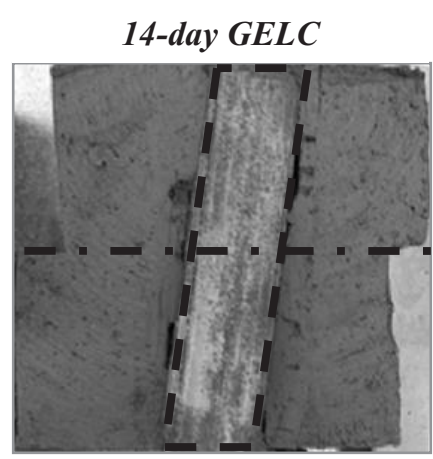

(i) 28-day GELC

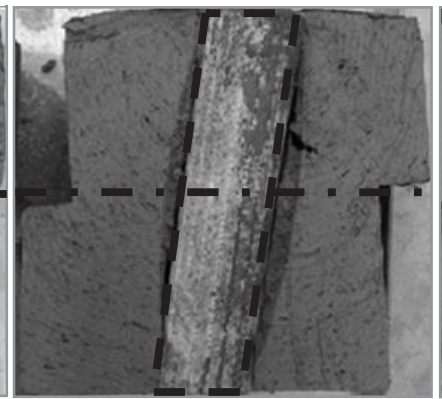

(ii) 56-day GELC

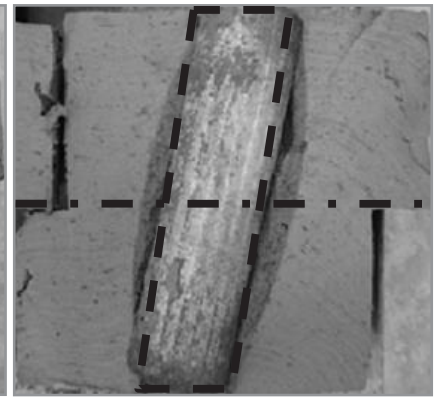

(iii)

Fig. 9. Bisected Pontian marine clay sample with $53 \mathrm{~mm}$ GELC

14-day GELC

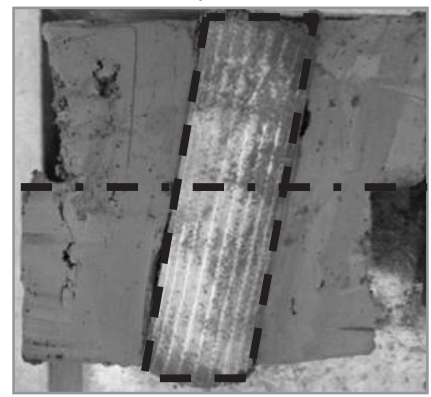

(i) 28-day GELC

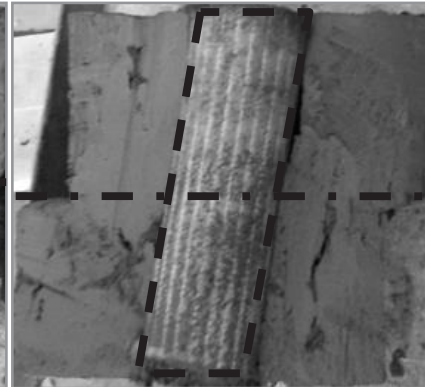

(ii) 56-day GELC

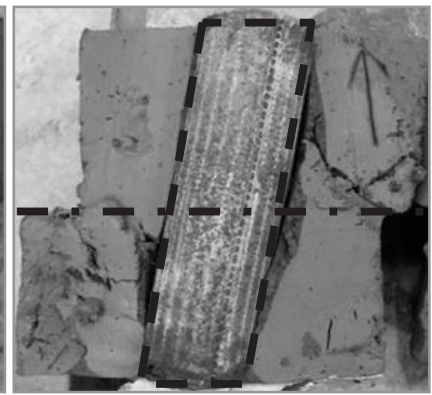

(iii)

Fig. 10. Bisected Pontian marine clay sample with $60 \mathrm{~mm} G E L C$ 


\section{Conclusions}

In conclusion, geotextile encapsulation effectively improved the horizontal shear resistance of lime column stabilized Pontian marine clay, especially for lime column with smaller sizes at younger ages, which was still in modification phrase when the column strength was still low. A 48\% increment was observed for lime column stabilized Pontian marine clay sample with area ratio of 0.036 , at age of 14 days. Meanwhile, the improvement ratio was near to 1 for sample at age of 56 days when the lime column was in stabilization phrase.

In terms of failure pattern, lime column at younger ages, namely 14 and 28 days, had shear failure. Whereas lime column at age of 56 days has bending failure with 2 plastic hinges. GELC at all ages had failure due to lacking of lateral resistance by the surrounding soil; the column was rotated. No crack was found on lime column with geotextile encapsulation. Geotextile encapsulation had protected lime column from shear and bending failure at early ages, which might lead to cracking and lateral displacement that reduced the load capacity of lime column.

\section{References}

1. S. Glendinning, C. Rogers, Deep stabilisation using lime (1996)

2. G. Rajasekaran, S. N. Rao, Soil and Foundations, 37, 97-104 (1997)

3. G. West, D. R. Carder, Review of lime piles and lime stabilised soil columns (1997)

4. Coastal Development Institute of Technology, The deep mixing method principle, design and construction (2002)

5. B. B. Broms, Ground Improvement, 252-330 (2004)

6. A. Arulrajah, A. Abdullah, M. Bo, A. Buoazza, Ground Improvement, 162, G11, 3-14 (2009)

7. B. B. Broms, Stabilization of soil with lime column. (1984)

8. M. Kivelo, B. B. Brom, Dry Mix Methods for Deep Soil Stabilization, 193-200 (1999)

9. S. Larsson, B. B. Broms, Proceedings of International Conference on Dry Mix Methods (2000)

10. M. Kitazume, K. Maruyama, The 17th International Offshore and Polar Engineering Conference (2007)

11. B. Charbit, Numerical analysis of laterally loaded lime/cement columns (2009)

12. J. Gniel, A. Bouazza, Geotext Geomembranes, 27, 167-175 (2009)

13. C. S. Wu, Y. S. Hong, Geotext Geomembranes, 27, 2, 107-120 (2009)

14. B. Idi, M. Kamarudin, “Asian Journal of Earth Sciences, 5, 2, 36-49 (2012)

15. S. Y. Chong, K. A. Kassim, EJGE, 19, K (2014)

16. S. Y. Chong, K. A. Kassim, EJGE, 19, A (2014) 